\section{Utilização de marcadores de DNA para o diagnóstico genômico de animais domésticos: 1 . Detecção da mutação pontual causadora da Deficiência de Adesão de Leucócitos Bovinos (BLAD) em gado Holandês no Brasil}

\author{
Use of DNA markers for genomic diagnosis of domestic animals: \\ 1. Detection of point mutation causing Bovine Leukocyte \\ Adhesion Deficiency (BLAD) in Brazilian Holstein cattle
}

CORRESPONDENCE TO

José Fernando Garcia

Departamento de Reprodução Anima Faculdade de Medicina Veterinária e Zootecnia da USP

Av. Prof. Dr. Orlando Marques de

Paiva, 87 - Cidade Universitária

Armando de Salles Oliveira

05508-900 - São Paulo - SP - Brasil

e-mail: jfgarcia@usp.br

Faculdade de Medicina Veterinária e Zootecnia da USP - SP 2 - Centro de Biotecnologia do Estado do Rio Grande do Sul da UFRGS - RS

\author{
José Fernando GARCIA'; André Sanches do Amaral GURGEL'; José Antonio VISINTIN' ;
} Vagner Ricardo LUNGE ${ }^{2}$; Isidro HOETZEL ${ }^{2}$

\title{
RESUMO
}

Analisaram-se 10 bovinos da raça Holandesa, descendentes da linhagem Ivanhoe. Submeteram-se os DNAs, purificados a partir de leucócitos destes animais, à técnica de Polymerase Chain Reaction (PCR) e posterior digestão com as enzimas de restrição Hae III e Taq I. Estabeleceu-se, desta maneira, o diagnóstico genômico da Deficiência de Adesão de Leucócitos Bovinos (BLAD). Os exames revelaram que 2 animais eram portadores e 8 , normais. A partir do desenvolvimento da metodologia de PCR, tornou-se disponível um método rápido, prático e eficiente para a seleção de touros em Centrais de Inseminação Artificial, por meio da detecção de animais portadores e normais.

UNITERMOS: Leucócitos; Bovinos; DNA.

\section{INTR ODUÇÃ O}

A Deficiência de Adesão de Leucócitos Bovinos (BLAD) é uma doença recessiva autossomal caracterizada pela grande redução na expressão das integrinas $\beta 2$ heterodiméricas dos leucócitos, resultando em múltiplos defeitos na função leucocitária. $O$ extravasamento de neutrófilos requer a interação entre as integrinas $\beta 2$ e as moléculas de adesão intercelular dos endotélios (Kishimoto et al. ${ }^{2}, 1989$; Arnaout', 1990; Von Andrian et al. ${ }^{6}, 1991$ ). Sem as integrinas $\beta 2$, os neutrófilos são incapazes de adentrar os tecidos e destruir os patógenos invasores. Conseqüentemente, os animais com BLAD sofrem infecções bacterianas freqüentes e recorrentes. A BLAD no gado Holandês é causada por uma mutação no gene da proteína CDI8 (uma subunidade da integrina $\beta 2$ ) que resulta na substiluição de uma glicina por um ácido aspártico na posição 128 da proteína (Fig. 1). Prevalente entre o gado Holandês $\mathrm{em}$ todo o mundo, essa mutação foi transmitida inicialmente por um famoso touro chamado Osborndale Ivanhoe, que viveu na década de 60 e foi amplamente utilizado na inseminação artificial, dando origem a uma das principais linhagens dentro da raça Holandesa. Posteriormente, alguns dos seus descendentes mais importantes também ajudaram na disseminação desta doença na população (Penstate Ivanhoe Star - fïlho - e Carlin-M Ivanhoe Bell - neto). No cruzamento entre dois animais heterozigotos (Aa), que são portadores do alelo mutante, existe a possibilidade de que $25 \%$ dos descendentes sejam doentes (aa), $50 \%$ portadores (Aa) e $25 \%$ livres da mutação (AA). Já no cruzamento entre um animal portador (Aa) e um animal normal (AA) teremos $50 \%$ dos descendentes portadores (Aa) e $50 \%$ dos animais livres do gene mutante (AA) (Fig. 2). A frequiência de D128G (nome do alelo mutante) entre o gado Holandês nos Estados Unidos é de aproximadamente $15 \%$ para touros e 6\% para vacas (Shuster et al. ${ }^{5}, 1992$ ).

A baixa frequiencia relativa do alelo mutante na população e os poucos sinais clínicos patognomônicos sugerem que grande parte dos bezerros com BLAD morrem sem diagnóstico. A maioria dos animais doentes morre com menos de 1 ano de idade e os que sobrevivem apresentam desenvolvimento retardado. Algumas vacas podem viver mais de 2 anos de idade, mas seu potencial reprodutivo e leiteiro é muito reduzido, pelo seu baixo ganho de peso e má saúde. Nos Estados Unidos, $80 \%$ das 10 milhões de vacas leiteiras são da raça Holandesa. Portanto, cerca de 16.000 bezerros nascem com BLAD a cada ano e a perda econômica média por bezerro é de US\$300.00. Assim bovinos com BLAD custam aos consumidores e produtores de leite US $\$ 5$ milhões anualmente, somente nos Estados Unidos, colocando a BLAD como a doença genética mais importante dentro da produção animal (Shuster et $a l .{ }^{5}, 1992$ ). A determinação da 


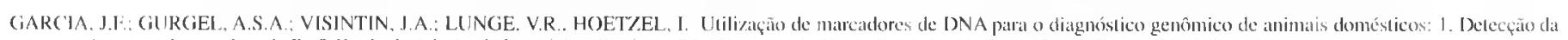

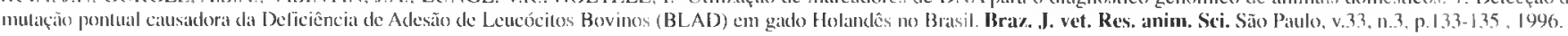

existência deste gene mutado na população de gado Holandês no Brasil é de suma importância para os criadores e lécnicos, para a escolloa correta dos reprodutores.

Com o advento de técnicas avançadas de manipulação de genomas, novos caminhos se abriram para o diagnóstico de doençass genéticas. Através da utilização da técnica de Polymerase Chain Reaction (PCR) (Saiki et al. ${ }^{3}$, 1988), pesquisadores adaplaram métodos precisos para o diagnóstico da BLAD (Shuster et al.5, 1992). Essa técnica permite a amplilicação exponencial da região do gene da integrina $\beta 2$ para posterior tratamento com enzimas de restrição, capazes de clivar os fragmentos de DNA amplificados no ponto onde ocorre a mulação causadora da BLAD.

O objetivo deste trabalho foi padronizar as técnicas de detecção de BLAD para posterior avaliação de possíveis porladores do gene deletério na população de bovinos Holandeses no Brasil.

Asp ${ }^{128}$
Alelo normal (A) ------ATC GAC CTG------
Alelo mutado (a)-----ATC GGC CTG-----
Gly ${ }^{128}$

Figura 1

Seqüências dos sitios de reconhecimento pelas enzimas de restrição Hae III (em negrito) e Taq I (sublinhada) para os alelos normal (A) e mutado (a) no locus CD 18 bovino. O sítio de clivagem está indicado por asterisco.

\section{MATERIAL E METODO}

DNA genômico foi purificado de amostras dé sangue de bovinos da raça Holandesa, colhidas com EDTA, utilizando protocolo clássico de lenol-clorofórmios (SAMBROOK et al. $\left.{ }^{4}, 1989\right)$. Os DNAs (20 ng) foram submetidos à técnica de Polymerase Chain Reaction (PCR) padrão (20) ng de DNA. Tay Polimerase - 2U, dNTPs 1,25 mM de cada nucleotídeo, oligonucleotídeos específicos - 5' TCCGGAGGGCCAAGGCTA 3' e 5' 'iAGTAGGAGAGGTCCATCAGGTAGTACAG 3'para a região do gene CDI 8 bovino onde ocorre a mutação 100) ng de cada, tampão apropriado para a enzima, volume linal $50 \mu \mathrm{l}$, coberto com 2 gotas de óleo mineral). Foram realizados 40 ciclos de amplificação $\left(94^{\circ} \mathrm{C}, 1 \mathrm{~min}\right.$; $55^{\circ} \mathrm{C}$, I min.; $72^{\circ} \mathrm{C}, 1 \mathrm{~min}$.). Após esta elapa, alíquotas de $20 \mu \mathrm{l}$ das reações de amplificação foram digeridas com I unidade das enzimas de restrição Hae III e Tay I (incubação por I hora a $37^{\circ} \mathrm{C}$ e $62^{\circ} \mathrm{C}$, respeclivamente) e submetidas à eletroforese $\mathrm{em}$ gel de poliacrilamida $20 \% \mathrm{em}$ tampão TBE $(4.5 \mathrm{mM}$ Trisborato e $\operatorname{lmM}$ de EDTA). O gel foi corado com brometo de elídeo $(0,5 \mu \mathrm{g} / \mathrm{ml})$ e os fragmentos de DNA visualizados em transiluminador ultravioleta.

\section{RESULTADOS}

Foram analisados 10 animais dos quais 2 foram portadores

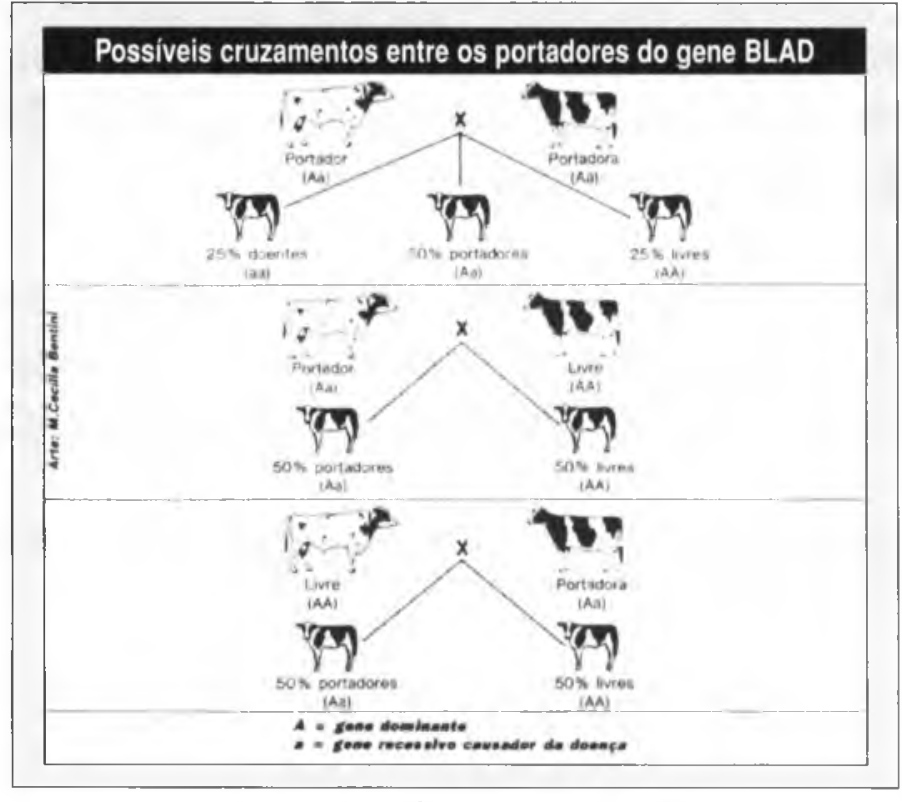

\section{Figura 2}

Possiveis esquemas de acasalamento entre animais por tadores de BLAD. A-alelo dominante e a-alelo recessivo. Animais homozigotos livres (AA), heterozigotos portadores (Aa) e homozigotos recessivos (aa) (arte de $M$. Cecilia Bentini - DBO Rural).

e 8 normais. A amplificação do DNA dos animais analisados gerou um fragmento de DNA de 58 pares de bases (pb). Observou-se em animais normais (AA), após a digestão com a enzima de restrição Tay I, 2 fragmentos de DNA, de 33 pb e 25 pb e após a digestão com a enzima de restrição Hae III. 2 fragmentos de DNA, de 49 pb e 9 pb; nos animais portadores (Aa), após a digesião com a enzima de restrição Taq 1 . 3 fragmentos ( $58 \mathrm{pb}, 33 \mathrm{pb}$ e 25 pb) e após a digestão com a

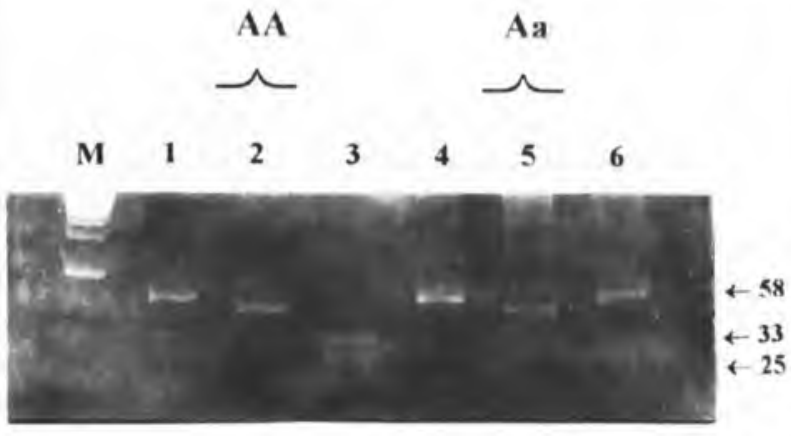

Figura 3

Eletroforese em gel de poliacrilamida $20 \%$ em TBE dos fragmentos amplificados por PCR e clivados com enzimas de restriçāo. Linha M: padrāo de peso molecular (escada de fragmentos de 100 pares de bases); Linhas 1, 2 e 3: resultado da amplificação de um animal livre (AA); Linhas 4, 5 e 6: resultado da amplificação de um animal portador (Aa). Linhas 2 e 5: fragmento clivado com a enzima Hae III e Linhas 3 e 6 fragmento clivado com a enzima Taq I. 
GARCIA JF. GURGEL. A.S.A.: VISINTIN, J.A.: LUNGE, V.R. HOETZEL, I. Utilização de marcadores de DNA para n diagnóstico genômico de animais domésticos: 1. Detecção då

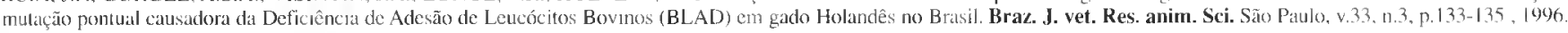

enzima de restrição Hae III, 4 fragmentos ( $49 \mathrm{pb}, 30 \mathrm{pb}, 19$ pb e 9 pb) (Fig. 3).

\section{DISCUSSĀO}

Com a adaptação da metodologia de PCR para a identificação de animais portadores de BLAD, tornou-se disponível um método rápido, prático e eficiente para a seleção de touros em Centrais de Inseminação Artificial. Com isso pode ser possível a utilização de sêmen de animais sabidamente negativos, para eliminar o gene deletério da população bovina dentro das próximas geraçõos.

Por ser a BLAD uma doença de caráter autossômico recessivo, ao acasalarem-se fêmeas portadoras (Aa) com touros lives da doença (AA), nunca haverá o nascimento de animais recessivos, obtendo-se na primeira geração $50 \%$ de possibilidade de animais portadores, na segunda geração $25 \%$, e na terceira geração $12,5 \%$ e assim sucessivamente (dentro do contexto populacional). Dentro de algumas gerações o número de portadores será desprezível e com a utilização de touros negativos será impossível obter animais doentes.

A análise dos resultados e montagem da árvore genealógi- ca dos animais avaliados (Fig. 4) confïmaram a ligação dessa doença genética com animais da linhagem Ivanhoe.

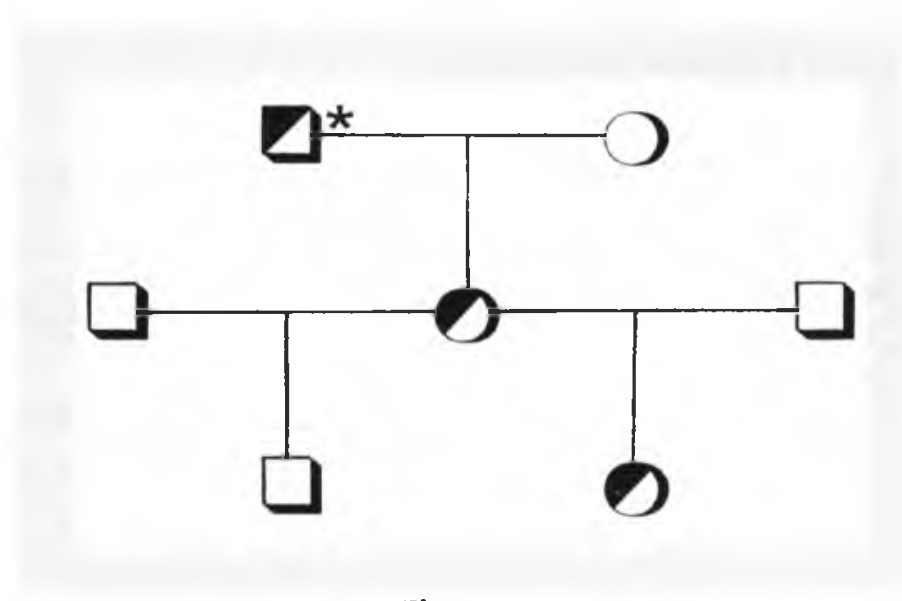

Figura 4

Árvore genealógica de animais portadores de BLAD mostrando sua relação com um touro ancestral portador (Carlin Ivanhoe Bell ${ }^{*}$ ). Quadrados representam machos e círculos representam fêmeas. Símbolos parcialmente preenchidos (Aa) e símbolos abertos (AA).

\section{SUMMARY}

Ten Holstein bovines, descendants from Ivanhoe line, have been analyzed. DNAs, purified from leukocytes of those animals, were submitted to Polymerase Chain Reaction technique (PCR) and digested by Hae III and Taq I restriction enzymes. Accordingly, the bovine leukocyte adhesion deficiency (BLAD) genomic diagnosis was established. The tests revealed that 2 animals were carriers and 8 were normal. Since the development of PCR methodology, a fast, practical and efficient way to select bulls in Artificial Insemination Centers has been through detection of carrier and normal animals.

UNITERMS: Leukocytes; Bovine; DNA.

\section{REFERÊNCIAS BIBLIOGRÁFICAS}

I-ARNAOUT, M.A. Structure and function of the leukocyte adhesion molecules CDI1/CDI8. Blood, v.75, p.1037-50, 1990.

2-KISHIMO'TO, T.K.: LARSON, R.S.: CORBI, A.L.; DUSTIN, M.L.; STAUNTON, D.E.: SPRINGER, T.A. The leukocyle integrins. Advances in Immunology, v.46, p.149-82, 1989.

3-SAIKI, R.K.; GELFAND. D.H.; STOFFEL, S.: SCHARF, S.J.: HICUCH, R.: HORN (i.T.; MULLIS, K.B.; ERLICH. H.A. Prime directed enzymatic amplification of DNA with a thermoslable DNA polymerase. Science, v.239, p.487-91, 1988 .

4-SAMBROOK, J.: FRITSCH. E.F.: MANIATIS. T. Molecular cloning: a laboratory manual. 2.ed. New York, Cold Spring Harbor Laboratory Press, 1989.

5-SHUSTER, D.E.; KEHRLI JUNIOR, M.E.; ACKERMANN, M.R. GILBERT, R.O. Identificalion and prevalence of a genetic defect that causes leukocyle adhesion deficiency in Holstein cattle. Proceedings of the National Acalemy of the Sciences of the United States of America, v.89, p.9225-9, 1992.
6-VON ANDRIAN, U.H.: CHAMBERS. J.D.: MCEVOY. L.M.: BARGATZE. R.F.: ARFORS. K.E.: BUTCHER, E.C. Two-step model of leukocyteendothelial cell interation in inflammation: Dislinct roles for LECAM-I and leukocyle $\beta 2$ integrins in vivo. Proceedings of the National Acalemy of the Sciences of the United States of America, .88 , p. $7538-42,1991$. 